Portland State University

PDXScholar

Summer 9-5-2013

\title{
Grouped to Achieve: Are There Benefits to Assigning \\ Students to Heterogeneous Cooperative Learning Groups Based on Pre-Test Scores?
}

Arman Karl Werth

Portland State University

Follow this and additional works at: https://pdxscholar.library.pdx.edu/open_access_etds

Part of the Educational Methods Commons, and the Interpersonal and Small Group Communication Commons

Let us know how access to this document benefits you.

Recommended Citation

Werth, Arman Karl, "Grouped to Achieve: Are There Benefits to Assigning Students to Heterogeneous Cooperative Learning Groups Based on Pre-Test Scores?" (2013). Dissertations and Theses. Paper 1412. https://doi.org/10.15760/etd.1412

This Thesis is brought to you for free and open access. It has been accepted for inclusion in Dissertations and Theses by an authorized administrator of PDXScholar. Please contact us if we can make this document more accessible: pdxscholar@pdx.edu. 
Grouped to Achieve: Are There Benefits to Assigning Students to Heterogeneous Cooperative Learning Groups Based on Pre-Test Scores?

by

\title{
Arman Karl Werth
}

A thesis submitted in partial fulfillment of the requirements for the degree of

\author{
Master of Science in Teaching \\ in \\ General Science
}

Thesis Committee:

Michael Flower, Chair

Melissa Potter

Howard Yank

Portland State University

2013 


\begin{abstract}
Cooperative learning has been one of the most widely used instructional practices around the world since the early 1980's. Small learning groups have been in existence since the beginning of the human race. These groups have grown in their variance and complexity overtime. Classrooms are getting more diverse every year and instructors need a way to take advantage of this diversity to improve learning. The purpose of this study was to see if heterogeneous cooperative learning groups based on student achievement can be used as a differentiated instructional strategy to increase students' ability to demonstrate knowledge of science concepts and ability to do engineering design. This study includes two different groups made up of two different middle school science classrooms of 25-30 students. These students were given an engineering design problem to solve within cooperative learning groups. One class was put into heterogeneous cooperative learning groups based on student's pre-test scores. The other class was grouped based on random assignment. The study measured the difference between each class's pre-post gains, student's responses to a group interaction form and interview questions addressing their perceptions of the makeup of their groups. The findings of the study were that there was no significant difference between learning gains for the treatment and comparison groups. There was a significant difference between the treatment and comparison groups in student perceptions of their group's ability to stay on task and manage their time efficiently. Both the comparison and treatment groups had a positive perception of the composition of their cooperative learning groups.
\end{abstract}




\section{TABLE OF CONTENTS}

Abstract i

List of Tables $\quad$ iv

List of Figures $\quad$ v

Chapter 1: Introduction $\quad 1$

Chapter 2: Literature Review 5

Differentiated Instruction $\quad 5$

$\begin{array}{ll}\text { Cooperative Learning Groups } & 7\end{array}$

Engineering Design 13

$\begin{array}{ll}\text { Chapter 3: Method } & 17\end{array}$

$\begin{array}{ll}\text { Overview } & 17\end{array}$

$\begin{array}{ll}\text { Participants } & 18\end{array}$

$\begin{array}{ll}\text { Treatment } & 19\end{array}$

Instruments

$\begin{array}{lr}\text { Pre-Test } & 21\end{array}$

$\begin{array}{lr}\text { Post-Test } & 23\end{array}$

Group Interaction Evaluation Form 24

Interview Form 25

$\begin{array}{ll}\text { Procedure } & 26\end{array}$

$\begin{array}{ll}\text { Data Analysis } & 28\end{array}$

$\begin{array}{ll}\text { Chapter 4: Results } & 30\end{array}$

$\begin{array}{ll}\text { Learning Gains } & 30\end{array}$

Student Perception of Cooperative Learning Groups 37

Interview Data 39 
Chapter 5: Discussion $\quad 42$

Interpretation of Findings $\quad 42$

Limitations 44

$\begin{array}{ll}\text { Conclusion } & 45\end{array}$

$\begin{array}{lr}\text { Recommendations } & 48\end{array}$

References $\quad \mathbf{5 0}$

Appendix A: Pre-Test

Appendix B: Post-Test

Appendix C: Interview Questions $\quad 56$

Appendix D: Group Interaction Evaluation Form $\quad 57$

Appendix E: Application and Approval for Human Subjects 59 


\section{LIST OF TABLES}

Table 1: Timeline and experimental design of this study

18

Table 2: Table 2: Average Students' Scores on the Pre- and Post-Tests with Students' Learning

Gains........

Table 3: Group Pre-Post Mean, Learning Gains, and SD Results by Quartile...............33

Table 4: Average Learning Gains Based On Learning Targets.....................................34

Table 5: Group Composition for Comparison Group.....................................................35

Table 6: Group Composition for Treatment Group....................................................36

Table 7: Group Interaction Form Mean, SD and t-test Results...................................38 


\section{LIST OF FIGURES}

Figure 1: Graph of Contrast Groups Average Pre-Post Data.........................................31

Figure 2: Graph of Average Learning Gains for Contrast Groups..................................32

Figure 3: Graph of Average Response to Group Interaction Questions by Contrast

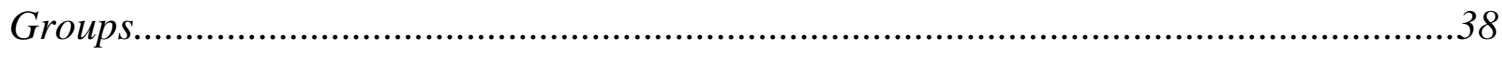




\section{CHAPTER 1: INTRODUCTION}

\section{Introduction}

Classrooms in the U.S. are becoming more diverse each year and instructors are in need of strategies to organize their classrooms so that cooperative group work can be done effectively. Differentiation is a method used by many instructors to try and account for these changing classrooms (Tomlinson \& Strickland, 2005). One means of differentiation can be cooperative learning groups; which were discounted and ignored prior to the early 1970's, but have now become one of the dominant instructional practices throughout the world (Johnson \& Johnson, 2009). However, there is a wide diversity in the way instructors group their students. The issue at hand is how to make these cooperative learning groups more effective in a diverse classroom. Heterogeneous cooperative learning groups based on student achievement can be a way to address this issue (Gillies, 2008). Students demonstrating a range of different levels of achievement will show more improvement in knowledge of science concepts while working in heterogeneous cooperative learning groups compared to randomly assigned cooperative learning groups.

Although small group learning has been practiced by humans for eons, there have been times in which cooperative learning has encountered considerable cultural resistance. There was a period of time from the 1940's to the early 1970's when the culture of the classroom in the U.S. revolved around "rugged individualism." This was the view that strong individuals were constructed by proving that they could learn by 
themselves without help from their classmates. Cooperative learning did not start to become widely practiced again until the early 1980's (Johnson \& Johnson, 2009).

Instructors have been widely using this practice around the world since it began to gain popularity again in the 1980's. The new issue that has become prevalent is how to use cooperative groups as effectively as possible. The way in which an instructor comprises learning groups within their classroom can be considered a differentiated instruction strategy. Tomlinson \& Strickland (2005) define differentiated instruction as a systematic approach to planning curriculum and instruction for an audience of academically diverse learners. Our classrooms are becoming more diverse every year. This diversity comes in the form of language, ability, gender, home environment, race, ethnicity etc. Instructional practices need to change to account for these ever changing variables within the classroom. One way in which this can be done is by using heterogeneous cooperative learning groups in the classroom. Gillies (2008) concluded that students within heterogeneous cooperative learning groups demonstrated more cooperative and on task behavior compared to the control group, which was an unstructured learning group.

Johnson \& Johnson (2009) suggest that social interdependence theory plays a major role in the success of cooperative learning groups. Social interdependence theory suggests that the outcomes of individuals are affected by their own and others' actions. This is the basis of cooperative learning groups. Cooperative learning groups tend to function ideally well because students are not only concerned about how their work is going to reflect the instructor's opinion of them, but also how their contributions to the 
group are going to affect the way their peers perceive them. Failing oneself is not the best feeling, but failing one's peers as well in addition to oneself is even worse. Johnson \& Johnson (2009) also found that an individual's sense of responsibility increases when there is group and individual accountability on a given task. Group accountability is when the work of the group is graded against a class-wide standard. Individual accountability is when the individual student's work is also graded and taken into account when giving an overall grade for a group project or report. This has been seen to increase overall student performance within groups. When creating these groups it is also essential that group sizes are not too large. As group size increases past four to five students, individual student performance goes down because individuals feel like their voices and input are not being heard (Johnson \& Johnson, 2009).

The proposed study will observe how students perform on an engineering design unit in a classroom comprised of heterogeneous cooperative learning groups based on student achievement from pre-test scores. This classroom will be compared to a different classroom completing the same unit but assigned randomly to cooperative learning groups. The independent variable is the method of student assignment to learning groups within the classroom. There are two dependent variables that will be looked at in this study. The first dependent variable is students' understanding of science content/process skills as measured by pre and post tests. The second dependent variable is students' positive or negative perceptions of their groups measured by a group interaction form. My hypothesis is that students in heterogeneous cooperative learning groups will have 
significantly greater pre-post gains and more positive attitudes towards the composition of their groups compared to the students in the randomized cooperative learning groups.

The reasoning behind my hypothesis is that students in heterogeneous cooperative learning groups will have students from all achievement levels on this particular subject. This will allow students who know more about the science concepts in this unit more chances to teach their classmates these concepts. Conversely, students who do not understand the concept as much as their classmates should have many more questions about how to solve a particular problem sparking dialogue within the group. When presented with an engineering design problem, students from all achievement levels should have thoughts about how to go about solving the problem. This diversity should create a rich pool of ideas to start solving the problem presented to the students. 


\section{CHAPTER 2: LITERATURE REVIEW}

\section{Review of Literature}

There are three areas of literature relevant to this study: differentiated instruction as a strategy to help all students, cooperative learning groups as a specific differentiated strategy, and engineering design as a means to teach science content.

\section{Differentiated Instruction}

Tomlinson and Strickland (2005) define differentiated instruction as "a systematic approach to planning curriculum and instruction for academically diverse learners" (Tomlinson \& Strickland, 2005, p. 6). The researchers stress the need for teachers to use differentiated approaches to address their classrooms while also accounting for both the complexity of their students' lives as well as the variety of their individual learning needs and or styles. There are five aspects of the classroom that teachers can differentiate, or modify to increase the likelihood that their students will learn more efficiently. The first being the content, followed by the process of teaching the content and students must be able to demonstrate their understanding. How students link thought and feeling within the classroom consists of the affect aspect. The last element refers to the learning environment, which consists of the feel and overall function of the classroom as a whole. Tomlinson and Strickland also suggest that quality curriculum is essential, all tasks should be respectful of each learner, students should always be challenged, make groups variable, be flexible in assessment practices, and leave room for growth (Tomlinson \& Strickland, 2005). 
Mastropieri et al. (2006) conducted a study to determine whether differentiated curriculum enhancements that were relevant to the topic of the scientific method could be developed for an inclusive eighth grade science classroom. The researchers tested these enhancements by using a class-wide peer mediated format to determine that if in a randomized field trial these enhancements would improve classroom test scores and scores on high-stakes tests. The researchers selected 13 eighth grade science classes that were matched to teachers and then randomly assigned the classes to either the control or experimental group. There were a total of eight teachers in this study, four were general education teachers (GET) and four were special education teachers (SPED). Each teacher taught at least one experimental and one control classroom. Of the 13 classes, five were co-taught by a GET and a SPED, and eight classes were taught by a single teacher (6 GET and 2 SPED). All GET held licensure as science teachers. There were 213 students in this study, 44 of whom were classified with disabilities (37 with learning disabilities and 7 with emotional/behavioral disorders) and 35 English language learners. Students in the control group were subject to teacher lecture, class notes, laboratory-like class activities and supplementary textbook materials on the scientific method. The experimental group had a differentiated curriculum on the same material but had three different levels of material scaffolded for different student abilities. The results showed that the difference between pre and post test scores of students in the experimental group and students in the control group were statistically significant $(\mathrm{p}<.05)$ and favored the experimental group. The results also showed a significant difference in the state's highstakes test scores (Mastropieri et al., 2006). 
In summary Tomlinson and Strickland (2005) state several strategies to differentiate classroom instruction practices. The need for differentiation in the diverse modern classroom is essential to the growth of all students. The educational system in the United States was set during a time of much less diversity and the system does not account for current or future levels of diversity. Differentiation is going to be a key tool for educators of the future. Mastropieri et al. (2006) conducted a study in an inclusive middle school science classroom that showed promising results for differentiating curriculum. Students in the experimental group, who received differentiated instruction, on average did better than their peers in the control group.

\section{Cooperative Learning Groups}

Johnson, Skon and Johnson (1980) conducted a study with the purpose of comparing the relative effects of cooperative, competitive and individualistic conditions on problem solving performance. The researchers were also interested in examining three possible influences on the problem-solving success of cooperative groups. These included the quality of the strategy used, how low and medium ability students benefit from having a high ability peer in their group and if there was increased incentive to succeed resulting from peer support and encouragement for achievement. The study was also set up to provide further validation for a set of instructional strategies. The sample consisted of two first-grade classes from a large suburban elementary school in a large Midwestern suburb. These two classes were made up of 45 students (27 male, 18 females). Groups were constructed using a stratified random sampling procedure making three groups (cooperative, competitive and individualistic groups), each group was made 
up of 15 students of mixed ability and gender. The cooperative group was made up of at least one high, one medium and low ability student as well as at least one female. The competitive group was structured to maximize competition, setting up situations for winners and losers. The individualistic group had students work alone and students were instructed to ignore others. All students participated in six instructional sessions of 60 minutes each, with each session being on a different day. Each group was asked to complete three different learning tasks, the first of which was a "categorize and retrieval" problem, followed by a spatial reasoning problem, and finally a verbal problem solving task. Results show that students in the cooperative group performed significantly better in all three categories.

\section{In Kagan's 1989 article "The Structural Approach to Cooperative Learning",} Kagan suggests that there needs to be a distinction between cooperative learning structures and activities. He defines structures as content free ways of organizing social interaction in the classroom. In other words, structures are ways to organize students into cooperative learning groups that could be applied to any type of content. He defines activities as a social context created for specific content, or cooperative learning groups that would only work for a particular lesson. An example of a structure would be a "Roundrobin". The function of this structure is to have team members express ideas and opinions; a way of getting acquainted with teammates. In this structure, each student takes turns sharing something with his or her teammates in a circular fashion. There are several different types of structures that can be used at different points in the cooperative learning process. One particular structure that is multifunctional is called "Co-op Co-op". 
In this structure, students work in groups to produce a particular group product to share with the whole class. This structure enforces individual accountability which creates an environment where every student makes a particular contribution to the group (Kagan, 1989).

Kagan \& Kagan (1998) use the acronym PIES which stands for the four basic principles of cooperative learning in the structural approach: Positive Interdependence, Individual Accountability, Equal Participation, and Simultaneous Interaction. Kagan suggests that when PIEs are incorporated in a cooperative learning setting, learning and other positive outcomes are more likely to occur. However, if an aspect is left out, positive outcomes cannot be guaranteed. When positive interdependence occurs, students view the success of a peer as a success of their own, this enhances collaboration. Individual accountability is also vital because if every individual in the group is not accountable for their own learning, a large portion of the groups responsibility can fall onto one or two individuals. Equal participation can be attained by giving every student in the group a role that has equal value within the group. This can be hard to implement if roles are not switched on a regular basis so all students can try certain roles.

Simultaneous interaction means that all students are actively engaged in the activity at the same time, meaning no individual is left out during the collaborative process (Kagan, 1998).

Robert Marzano, Debra Pickering, and Jane Pollock co-authored a book in 2001 called "Classroom Instruction that Works". The authors summarize research and theory and use that information to generalize classroom practice. They describe nine different 
teaching strategies which have been proven to have positive effects on student learning. Among those strategies is cooperative learning. One of the key themes that kept coming up in the literature was that organizing students into cooperative learning groups has a powerful affect on learning, regardless of whether or not the groups compete with one another (Marzano, Pickering \& Pollock, 2001).

Research by Dean, Stone, Hubbell, \& Pitler (2012) added to the work of Marzano et al. (2001) in their second edition of "Classroom Instruction that Works: ResearchBased Strategies for Increased Student Achievement". This recent publication reviewed literature from several different areas of instructional practice, including cooperative learning. The authors cite Johnson and Johnson (1980 \& 2009), as well as Kagan (1989), and several other authors work on cooperative learning. Some essential elements to cooperative learning that they found in their review of the recent literature were that positive interdependence and individual accountability are the two most important of the five elements identified by Johnson and Johnson (2009). Another keynote highlighted was the importance of small group size, and the use of cooperative learning groups consistently and systematically. The authors state that "cooperative learning provides an environment in which students can reflect upon their newly acquired knowledge, process what they are learning by talking with and actively listening to their peers, and develop a common understanding about various topics" (Dean et al., 2012).

Gokhale (1995) conducted a study whose purpose was to examine the effectiveness of individual learning versus collaborative learning in enhancing drill-andpractice skills and critical-thinking skills on the subject of parallel dc circuits. 
Collaborative learning is defined as an instruction method in which students work in groups toward a common academic goal. Critical thinking is defined as thinking that involves analysis, synthesis, and evaluation of concepts. Drill and practice items are items that pertain to factual knowledge and comprehension of concepts. The questions Gokhale was addressing were: will there be a significant difference in achievement on a test comprised of "drill and practice" items between students learning individually and students learning collaboratively? Will there be a significant difference in achievement on a test comprised of "critical-thinking" items between students learning individually and students learning collaboratively? The treatment in this study was made up of two categories: individual learning and collaborative learning. The outcome variable being measured was how well students performed based on their post test score. The study was conducted on undergraduate students in industrial technology at Western Illinois University. The students were enrolled in a basic electronics course. The study was conducted on two sections of the course; each section had 24 students making a sample of 48 students. The study focused on the difference between a pretest administered to all subjects prior to the treatment and a post test administered at the end. A nonequivalent control group design was used in the study. The findings of the study were that there was no significant difference between students' scores on the drill and practice test ( $\mathrm{p}$ value .09) using a t-test. The results for the t-test on collaborative learning showed a significant difference that collaborative learning groups helped students improve their critical thinking skills with a p-value of $<.001$. It was found that students who participated in 
collaborative learning had performed significantly better on the critical- thinking test than students who studied individually.

Gillies (2008) conducted a study whose purpose was to investigate if there are differences in how students behave, interact and learn when they work in groups that are structured and groups that are not structured during science-based inquiry. A structured group was defined as a group where tasks are established so that all members know how they can contribute, and small group skills are required to help students communicate effectively with their peers, manage conflict, allocate resources fairly and make decisions democratically. An unstructured group is one where these elements are not present. Participants in the study were $1649^{\text {th }}$ grade students (77 students in the structured group and 87 students in the unstructured group) from six high schools in Brisbane, Australia. Groups consisted of four students unless a student was absent during the time the research team visited to videotape. This meant that some groups only had three members. Both groups were made up of students that tested similarly on an achievement scale before the intervention began. The groups were made up of one student from the upper quartile of achievement, one student from the lower, and two students from the middle or average achievement level. The study was done for one period for four to six weeks each term across the school year. The structured group and the unstructured group were given a task to organize their knowledge of local television programs into specific categories and sub-categories and to indentify additional sub-categories based on specific attributes. The student's behaviors were measured by behavioral observations and verbal interactions. The results showed that students who worked in structured, cooperating 
groups demonstrated more cooperative behavior and less individually-oriented behavior and off task behavior than the students in the unstructured groups. The limitations of this study were that the students' behaviors were only collected at one point in time, during the last two weeks of their instructional unit, also, the teachers were never observed to see how well they instructed their students in how to collaborate in small structured groups.

In summary there is strong evidence that cooperative learning groups support student learning in the classroom. These groups help all students who participate, from the students who are below average to the high achievers. When conducted correctly, all students have knowledge to bring to the situation to help the group as a whole. This aspect of learning can be very important to students who may not be as confident as their peers.

\section{Engineering Design}

Gattie and Wicklein (2007) conducted a survey that addressed three key issues related to technology and engineering design in the classroom. These issues include: the current practices of technology teachers in relation to utilizing engineering design practices within the high school technology education classroom; the value of an engineering design focus for technology education; and the instructional needs of high school teachers of technology education related to engineering design. An instrument used was a survey of high school teachers concerning their use of technology and engineering design. The study began with a population of 1063 in-service high school 
technology instructors who were members of the International Technology Education Association (ITEA) and selected for this study. From this initial sample, 583 teachers were selected from four different areas around the country. The sample was made up of only ITEA members so the results cannot be generalized to the entire population of technology teachers. The researchers received a total of 283 usable surveys that were analyzed. Results from the survey show that this sample of teachers expressed confidence that an engineering design curriculum focus would add value to the field of technology education by clarifying the focus of the field (93\% agreement); providing a connection with other school subjects and content ( $96.7 \%$ agreement); elevating the field to higher academic levels (92.7\% agreement); improving instructional content (88.4\% agreement); increasing student interest in mathematics and science (89.3\% agreement); and providing additional learning opportunities for students (94.4\% agreement). Engineers work in groups to design solutions to real world problems. This survey found that teachers believe there is value in engineering and technology education, and that there is a need for engineering design to be taught at the high school level. Cooperative learning can be a means to teach the design process.

Mehalik, Doppelt, and Schunn (2008) were trying to find out which approach to teaching a unit on electricity would be more affective; scripted scientific inquiry or the systems design approach (engineering design). The questions that the researchers were trying to answer were; will the systems design approach increase student performance compared to scripted scientific inquiry? Will the systems design approach benefit any specific demographics? The researchers used a paired experimental/contrast design in 
which 10 teachers and 587 students ( 26 classes) implemented the system design approach with the Alarm System module (design group), and five teachers and 466 students (20 classes) followed the scripted inquiry approach with the scripted inquiry Electricity unit (inquiry group). Both groups are from the same pool of 27 science teachers at the 8th grade level in an urban district in the Northeast U.S. The researchers pointed out the main difference between the two groups of teachers, the design group was provided with more incentives to partake in the study compared to the inquiry group. These incentives included paid professional development (PD) and the option to earn continuing education credits for their participation in the systems design PD. The teachers who made up the inquiry group had already been trained in how to teach the unit by the district for the previous three years; making this group more of a voluntary group. Each group has students matched nearly evenly in the high socioeconomic status (SES) range but the four lowest SES schools in the district are in the design group. However, to try and offset this, the researchers put a lower proportion of students in the middle SES range (14\% vs. $38 \%$ ) in the design group. Students were given pre and post tests to measure changes in student knowledge of electricity concepts. The researchers created a knowledge test that was designed around the core concepts in electricity in order to make sure that both the design group and the inquiry group would be evaluated on the content knowledge for which the guided inquiry approach focused. Both groups were given a pre-test the day before the 45 week unit began and a post test the day after the 4-5 week unit finished. The design groups' pre-post scores were twice as high as the inquiry group. The design group showed an average gain of 16 percent versus the inquiry group gain of 7 percent. The systems 
design approach was most helpful for low-achieving African American students, although it was at least as good as and typically better than scripted inquiry for all students.

In summary educators at the high school level as well as the middle school level express the need for the engineering design process to be taught in technology courses, and to be blended with science content. Engineering design can be an effective way of teaching science content in a hands-on way that is appealing to students who would like to express their creativity in solving a problem. The process allows students to think critically about science content while also focusing on solving real world problems that bring relevance to content.

This study will combine aspects of cooperative learning groups, differentiated instruction, and the engineering design process to help students better understand science content through the engineering design process. The question the study will address is: does the method of student assignment to cooperative learning groups (heterogeneous vs. random) in an inclusive middle school science classroom make a difference in students' ability to use the engineering design process and understand science concepts? 


\section{CHAPTER 3: METHOD}

\section{Overview}

This was a quasi-experimental mixed-methods study to address the question: does the method of student assignment to cooperative learning groups in an inclusive middle school science classroom make a difference in students' ability to understand the engineering design process, science concepts and have an effect on student perceptions of their groups? Two intact classes were involved in the study, and students in both the experimental and treatment groups were assigned to cooperative learning groups for this unit.

The independent variable was the method of student assignment to learning groups within the classroom. In one class, students were assigned randomly. In the other class groups were assigned based on pre-test scores, so that each group was composed of students with a range of knowledge on the topic of the unit.

The first dependent variable was student-ability to use engineering design to understand science content. The data collected was pre- and post-test scores for both groups, which measured student understanding of science concepts based on the content covered in the unit in which this study was conducted. The second dependent variable was students' positive or negative perceptions of their groups measured by a group interaction form. The collected data was students' perceptions of their groups based on a group interaction form, which asked two survey questions based on a one to four scale. Qualitative data was also collected using student interviews to see what the strengths and weaknesses of the group teaching method were; and whether or not there was a difference 
from the students' point of view in how students were assigned to groups. The experimental design is shown below.

Table 1: Timeline and experimental design of this study

\begin{tabular}{|l|l|l|l|}
\hline Experimental Group $\left(\mathrm{N}_{\mathrm{a}}\right)$ & $\mathrm{O}_{1}$ & $\mathrm{X}_{1}$ & $\mathrm{O}_{2,3,4}$ \\
\hline Comparison Group $\left(\mathrm{N}_{\mathrm{b}}\right)$ & $\mathrm{O}_{1}$ & $\mathrm{X}_{2}$ & $\mathrm{O}_{2,3,4}$ \\
\hline
\end{tabular}

$\mathrm{N}_{\mathrm{a}}$ Non-Randomized Study Group A. $\mathrm{N}_{\mathrm{b}=}$ Non-Randomized Study Group B. $\mathrm{O}_{1}=$ PreTest on Content. $\mathrm{O}_{2}=$ Post-Test on Content. $\mathrm{O}_{3}=$ Interviews. $\mathrm{O}_{4}=$ Perceptions for group interaction. $\mathrm{X}_{1}=$ Cooperative Group (Pre-Test Scores). $\mathrm{X}_{2}=$ Cooperative Group (Random Assignment)

\section{Participants}

The participants in this study were eighth grade students from a K-8 school within a large urban school district located in Portland, Oregon. This school is located in a predominantly middle class neighborhood. The class periods were 65 minutes long and met Monday through Friday unless there was a holiday or field trip. The participants were from two different class periods covering the same content. The treatment group consisted of 22 participants and the comparison group consisted of 10 participants. Overall, the student body this K-8 school is made up of 7.5\% African American, $11.4 \%$ Asian/Pacific Islander, 7.6\% Hispanic, 1.9\% Native American/Alaskan Native, 67.2\% White, and $4.4 \%$ of students belong to multiple ethnicities. The school also has $14.6 \%$ of their students in the Special Education program, $9.3 \%$ are TAG, and 38.7\% are on free and/or reduced lunch (PPS, 2011).

These groups were selected based on my student teaching placement through Portland State University in partnership with the district. This particular school only had two periods of 8th grade science, and the content and curriculum of this grade band was a good match for this project. Students were assigned to either the comparison or treatment 
group based on their class schedule. The comparison group consisted of the third period, while the treatment group was fifth period. Participants were assigned to cooperative learning groups based on their pre-test scores in the treatment group, and randomly for the comparison group.

\section{Treatment}

Both classes were taught the same science unit on earthquakes and earthquake safe homes. In addition, both classes were organized in small groups during the unit, which was completed in three weeks. The unit involved an engineering design project as the main task. Students were presented with a problem and had to work collaboratively in their groups to design a solution to that problem.

All students took a pre-test at the start of the unit. Students in the experimental class were assigned to cooperative learning groups based on their pre-test scores. Students were grouped based on their knowledge of the science concepts and engineering design process that was evaluated by their demonstration of knowledge on a pre-test. Each group was made up of low, medium, and high level students based on their pre-test scores. This method of assignment is designed to create differentiated cooperative learning groups so that students who have more knowledge of the topic can help others. The control (comparison) class was randomly assigned to small groups using a random group generator. The purpose of this treatment was to see if groups intentionally comprised of students who have a varying range of knowledge about the topic, could help all students do better collectively within the scope of an engineering design project. The 
treatment was implemented at the start of the unit after the students had completed a pretest on science concepts related to the engineering design project.

Another difference between these two groups was that the treatment group consisted of some students who were taking Algebra I for high school credit and students who were in regular eighth grade math. These students also have science directly after their lunch break. The comparison group consists of only students who are in regular math and have science before their lunch break.

\section{Instruments}

Three separate instrument types were used to collect qualitative and quantitative data. Student learning gains were measured by the difference in pre-post test scores. The pre test (Appendix A) and post test (Appendix B) were constructed based on the science concepts and the engineering design process skills learned during the unit. The pre-test was a quantitative measurement tool used to group students in the treatment group based on their ability. The post-test was also used as a quantitative tool to measure the learning between the start of the unit, the intervention and the end of the unit. At the end of the unit, after the post-test was given, participants were given a Group Interaction Evaluation Form (Appendix C). This form was used to collect both quantitative and qualitative data on student perceptions of their groups. The last instrument used was a questionnaire (Appendix D) that was used as a means of collecting qualitative data. Interviews were conducted using a questionnaire to measure student attitude towards the composition of their groups compared to the students in randomized cooperative learning groups. The 
questions within the questionnaire left room for the interviewer to ask follow-up questions based on student response to the structured questions.

\section{Pre-Test:}

Appendix A is a copy of the pre-test administered at the beginning of the unit. The test consists of six questions and is broken into three parts. There were three multiple choice questions and three short constructed responses. Part 1 is the design process which consists of two questions that address the correct order of the process and the difference between information that is a piece of criteria or a constraint. The questions in Part 2 address science concepts related to building earthquake safe homes which will be taught during the course of the unit. The last section of the test has one question that is related to types of stress. The concept of stress, particularly tension and compression, were taught in a previous unit; but related to the surface of the earth and not to building materials. This question was used to see if students could make the connection to their previous learning. This pre-test was developed with the Next Generation Science Standards (NGSS) and the Oregon Department of Education (ODE) science standards in mind. The questions were designed to be aligned with the MS-ESS3.2 content standard and the MSETS1-1 engineering design standard from the NGSS. These ODE science standards were also taken into consideration: content standard 8.2E.2 and the engineering design standard 8.4.

The document within Appendix A also shows the mark scheme used to assess the test for all of the questions except the last. The last question was worth three points, 
which required them to correctly label areas of compression and tension. I was looking to see if the students could correctly draw the supports necessary to alleviate stress while still having a practical design. The question was graded on a proficiency scale. Students earned one point if they attempted but were missing major parts or the ideas were too far off, two points if they had the right idea but key points were still missing, and three points if they demonstrated that they knew where compression and tension were taking place and what kinds of supports that would practically alleviate the stress.

This instrument was used with each study group before the intervention. Students in the treatment group were placed into cooperative learning groups based on their pretest scores. The test was out of ten points and the highest score on the test in the treatment group was a seven out of ten. I used this high score to create a means of breaking up the class into high, medium and low cooperative learning groups of three to four students. If students scored a 1-3, they were put into the "low" category. If they scored a 4-5, they were put into the "medium" or "average" category, and if they scored above a 5 they were put into the "high" category. This process followed what Gillies (2008) had done when they grouped their students into upper, middle, and lower quartiles and making sure that each group had at least one student from the upper and lower quartiles.

Reliability of this instrument was taken into consideration by making copies of five different participants' pre-tests and having my mentor teacher and I grade those five tests independently. My mentor teacher and I then discussed the scores we gave for each question and calibrated our answer key accordingly. This helped make the instrument more reliable. Face validity was determined by the judgment of two education 
professionals in science at my placement school who agreed that the instrument provided a satisfactory measurement of student understanding of learning targets for this unit.

\section{Post-Test:}

Appendix B is a copy of the post-test with an answer key which was administered at the end of the unit. The test consists of ten questions. There were seven multiple choice questions and three short constructed responses. The first seven questions on the test address student understanding of the engineering design process and the scientific concepts presented in the unit. The first two constructed response questions assess student knowledge of concepts presented during the course of instruction for the unit. The last question on the assessment had students think about their teams and how well each team worked together to solve the problem. The post-test was worth 14 points, each multiple choice question was worth one point and the first two constructed response questions were worth two points each. The last question was broken into three parts and was worth one point for each part for a total of three points.

This instrument was used to assess the learning of each student in both groups over the course of the unit. The scores from this test were compared to each participant's pre-test score to see how their learning improved after the treatment and a unit of instruction. All participants in both the treatment and comparison group were initially categorized into a low, medium, or high quartile. The post-test scores were compared to the pre-test scores for each student in each quartile, which allows for comparison between the two groups. 
This post-test was developed with the Next Generation Science Standards (NGSS) and the Oregon Department of Education (ODE) science standards in mind. The questions were designed to be aligned with the content standard MS-ESS3.2 and the engineering design standard MS-ETS1-1 from the NGSS and the content standard 8.2E.2 and the engineering design standard 8.4 from the ODE science standards.

Reliability of this instrument was taken into consideration by making copies of five different participants' post-tests and having my mentor teacher and I grade those five tests independently. My mentor teacher and I then discussed the scores we gave for each question and calibrated our answer key accordingly. This helped make the instrument more reliable. Face validity was determined by the judgment of two education professionals in science at my placement school who agreed that the instrument provided a satisfactory measurement of student understanding of learning targets for this unit.

\section{Group Interaction Evaluation Form:}

The Group Interaction Evaluation Form can be viewed in Appendix C. This form asks students to evaluate the way that their group interacted and cooperated with one another. The purpose of using this form was to address the question of how student perception of their learning groups was affected by the composition of their group. Students were not aware of the composition of their group at any point in this study. However, I wanted to see if there was any connection to positive perception and heterogeneous grouping. This particular instrument was adapted from the Science Education for Public Understanding Program (SEPUP) curriculum (Bellantoni et. al, 
2012). The instrument asks students to answer two survey statements with a rating of 1-4. The students are then asked to write two short answer questions that unpack and explain their answers to the survey statements. The two statements are:

1. Group stays on task and manages time efficiently.

2. Group shares opportunities to contribute.

These answers were used to determine whether or not heterogeneous grouping made a positive impact on students' perceptions of their groups. The reliability of this instrument was determined by its use in the SEPUP curriculum. My mentor teacher was asked to review the adapted document for face validity.

\section{Interview Questionnaire:}

The interview questionnaire can be viewed in Appendix D. Six students were interviewed at the end of the instructional unit. All students had received three full weeks of experience working with their team to solve a problem, and instruction on concepts related to the unit. All of the students had completed their post-test and Group Interaction Evaluation Form prior to the interview. Five open-ended interview questions were asked of the participants, with follow-up questions for clarification if necessary. The six interviewees did not represent a statistically significant proportion of the study sample size and responses were used to add qualitative depth to responses to the evaluation form. These interview questions were designed to evaluate student's perceptions of the interaction within their groups and a basic understanding of the problem we were trying to solve. The following questions were asked of each student: 
1. Do you remember the question your group was trying to address in our design activity? If so, can you explain it to me? (Follow up with a reminder if student cannot answer)

2. How did your group go about trying to solve the problem?

3. What did each of the members of your group contribute while trying to answer the problem? What did you contribute?

4. Can you imagine trying to design a solution to a similar problem by yourself? What are some of the pros and cons of solving this problem as a group compared to solving it on your own?

5. Is there something that you learned from a group member that you did not know before you started this project?

Interview responses were evaluated for recurring themes and used for a more in

depth look at student answers to the Group Interaction Form. The validity of these interview questions was evaluated by peers in my research cohort and by a science education research professional. Three students were interviewed from each experimental group. Students in the comparison group were selected based on availability to be pulled out of class and having submitted a permission form. Students in the treatment group were selected based on availability and being a part of the same heterogeneous cooperative learning group.

\section{Procedure}

This study took place during a three-week period in the 2012-2013 school year coinciding with my student teaching. It is designed to take place at the beginning of a new unit of instruction. Two different classes were selected based on similar student demographic characteristics to the extent possible. These classes were labeled as the experimental group $\left(\mathrm{N}_{\mathrm{a}}\right)$ and the comparison group $\left(\mathrm{N}_{\mathrm{b}}\right)$. Both groups were given a pretest on the content related to the new unit. Both groups had class periods that were 65 minutes in length. 
The pre-test scores for $\mathrm{N}_{\mathrm{a}}$ were used to create eight differentiated cooperative learning groups for an engineering design unit. The groups were comprised by selecting high, average, and low scoring students based on pre-test scores to be in the same group. Ideally these groups would consist of no more than four students. In this study, groups consisted of three to four students depending on class size. This is the treatment $\left(\mathrm{X}_{1}\right)$.

The comparison class was split into seven cooperative learning groups based on a computer program that randomly assigns students to groups of four. The groups were also cross checked with their pre test scores to make sure that they did not end up with a similar structure to the experimental group. The groups consisted of a variety of different compositions and were not heterogeneous as a whole. This is the treatment $\left(\mathrm{X}_{2}\right)$ for the comparison group.

Students were notified of their new group assignments on the first day of their engineering design project. They were instructed to find their new teammates by locating their own name at one of the table stations in the classroom. No information on how the groups were created was communicated to the students. The students worked in these groups during the duration of the engineering design project, solving a problem of creating an earthquake safe home with a limited supply of materials that could withstand shaking for a specific time on a shake table. This project was laid out and completed within a packet that had a low rate of return at the end of the project, so the data within the packet was not used. After the completion of the unit, students were also given a group interaction form to complete. This form was used to measure student perception of their groups as being positive or negative. 
Both the experimental and comparison groups were given a post test on science content related to their engineering design unit $\left(\mathrm{O}_{2}\right)$. These post test scores will be compared with pre-test scores to see if there is a significant difference between the implementation of $\mathrm{X}_{1}$ and $\mathrm{X}_{2}$. Student interviews $\left(\mathrm{O}_{3}\right)$ were conducted within one week after the conclusion of the engineering design unit. Two students from $\mathrm{N}_{\mathrm{a}}$ and three from $\mathrm{N}_{\mathrm{b}}$ were selected for interviews based on positive change in pre-post scores, or lack thereof. The interviewees were asked questions related to how they felt about the configurations of their groups and their ability to do the engineering design process.

\section{Data Analysis}

Descriptive and inferential statistics were calculated for the collected data. Learning gains were calculated for both contrast groups. This was done by finding the difference between post-test scores and pre-test scores for every individual student. These scores were then averaged to find the mean. The standard deviation was also calculated for both contrast groups. A t-test was calculated for these two groups to see if the results were statistically significant. Tables and graphs were created for this data and can be viewed in the results section.

A second form of analysis was done by disaggregating the data into the three different categories: "low", "med", and "high" for each contrast group. The same analysis was performed on the disaggregated data to find the mean, and standard deviation for each category. A table and graph were created to better represent the analyzed data. 
To calculate students' perceptions of their cooperative learning groups interaction with one another, the scores from the Group Interaction Evaluation Form (Appendix C) were analyzed. For each contrast group, the mean and standard deviation was calculated for the first two questions on the form. A t-test was also used to see if the perceptions were statistically significant for each question. 


\section{CHAPTER 4: RESULTS}

\section{Learning Gains}

Overall gains in students' learning over the course of the unit were determined by the difference between the post-test and pre-test scores. For class results, all student pre and post test scores were averaged for both the comparison and treatment groups. This information can be viewed in Table 2 below. The t-test for the learning gains for the treatment and comparison groups resulted in a p-value of 0.42 . The mean post-test scores for the comparison and treatment groups were 63 percent and 69 percent respectively.

Table 2: Average Students' Scores on the Pre- and Post-Tests with Students' Learning Gains

\begin{tabular}{lcc}
\hline \hline & $\begin{array}{c}\text { Comparison Group } \\
(n=10)\end{array}$ & $\begin{array}{c}\text { Treatment Group } \\
(n=22)\end{array}$ \\
\hline Pre-Test & $35 \%$ & $40 \%$ \\
Mean & 2.01 & 1.60 \\
SD & & \\
Post-Test & $63 \%$ & $69 \%$ \\
Mean & 2.47 & 2.19 \\
SD & & \\
Learning & $28 \%$ & $29 \%$ \\
Gains & & \\
\hline
\end{tabular}

*Note $\mathrm{p}>0.05$

The data in Table 2 is represented visually in Figure 1 below. The comparison and treatment groups mean pre-test scores were five percent different and their mean post-test scores were six percent different. 


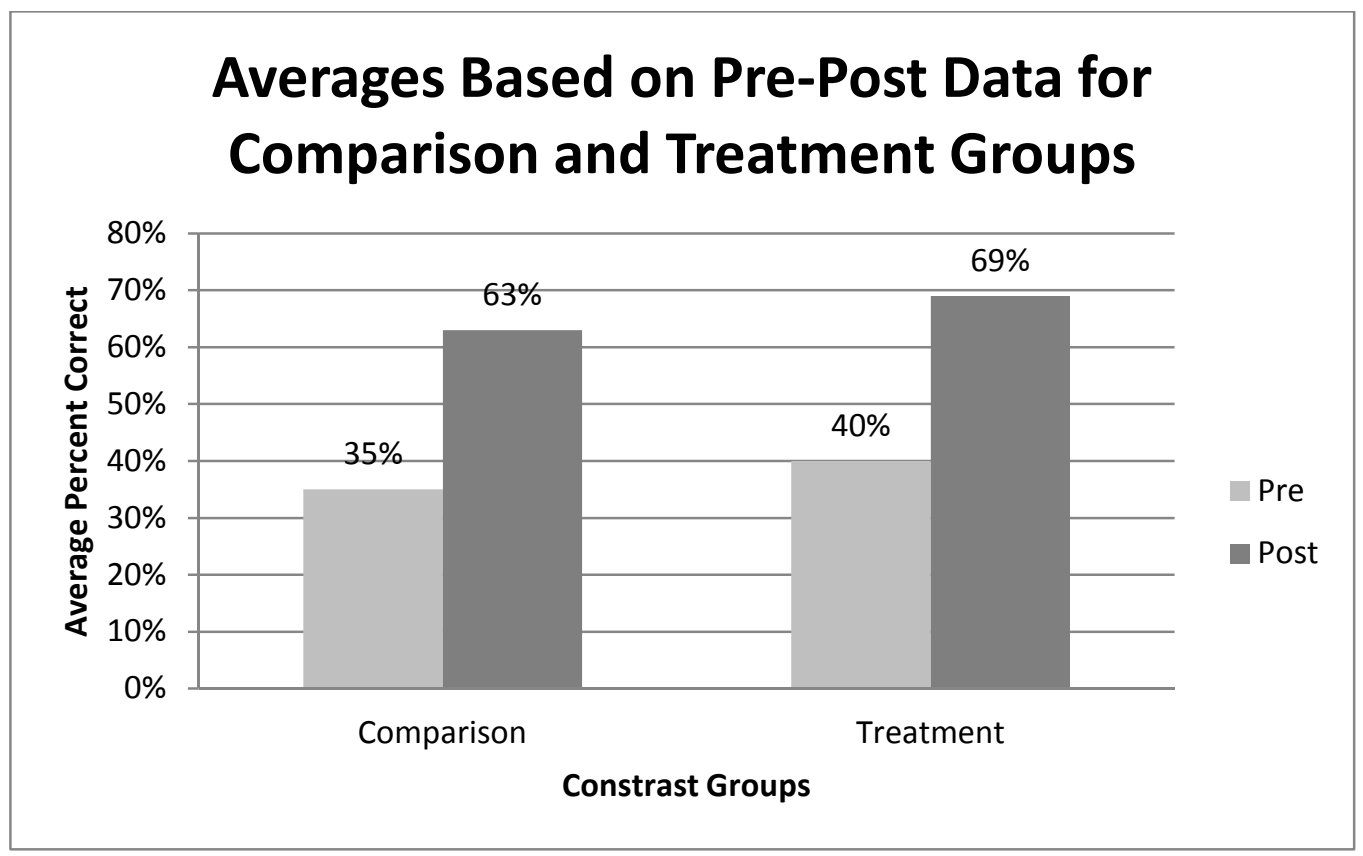

Figure 1: Graph of Contrast Groups Average Pre-Post Data

The disaggregated average learning gains based on heterogeneous cooperative learning groups are represented in Figure 2 below. On average, the students in the "low" category of the comparison group scored eight percent better than the students in the treatment group. The sample size for the "low" category for the comparison group was five students, compared to the 11 students in the same category of the treatment group. The "med" category had similar results in the opposite direction. On average, the students in the "med" category for the treatment group had six percent higher learning gains compared to their counterparts in the comparison group. The learning gains for students in the "high" category of the comparison group were a negative six percent compared to a positive 12 percent for the treatment group. 


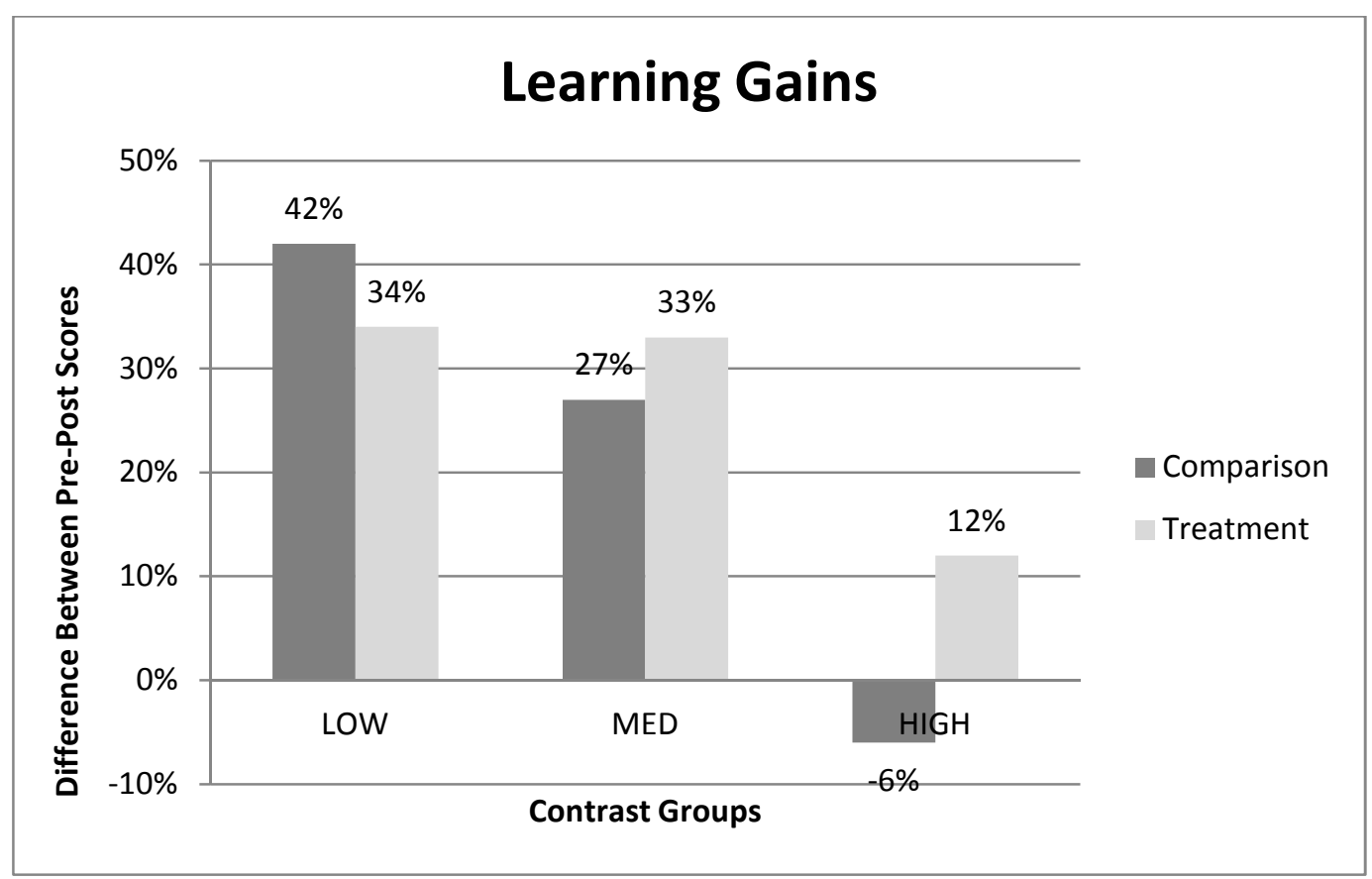

Figure 2: Graph of Average Learning Gains for Contrast Groups

Table 3 below shows the data that is represented in the graph above. The sample size for the "high" category was made up of two students, compared to the five students in the treatment group. One of the two students in the comparison group had a - 24 percent learning gain when comparing the pre and post test scores. The other student in the group had a positive 11 percent learning gain which averages to negative six percent.

The mean post-test score for students in all categories of the treatment group were greater or equal to that of the comparison. The post-test averages for the "low" category for both the comparison and treatment groups had the same value of 62 percent. The average post-test score for the "med" category of the treatment group was 77 percent compared to the 67 percent of the comparison, a 10 percent difference. The post-test 
averages for the "high" category of the treatment group were 76 percent compared to the 59 percent of the comparison group, a 17 percent difference.

Table 3: Group Pre-Post Mean, Learning Gains, and SD Results by Quartile

\begin{tabular}{|c|c|c|c|c|c|c|}
\hline \multicolumn{4}{|c|}{ Comparison } & \multicolumn{3}{|c|}{ Treatment } \\
\hline & $\begin{array}{l}\text { Pre-Test } \\
\text { Average }\end{array}$ & $\begin{array}{l}\text { Post-Test } \\
\text { Average }\end{array}$ & $\begin{array}{c}\text { Average } \\
\text { Learning } \\
\text { Gains }\end{array}$ & $\begin{array}{l}\text { Pre-Test } \\
\text { Average }\end{array}$ & $\begin{array}{c}\text { Post-Test } \\
\text { Average }\end{array}$ & $\begin{array}{c}\text { Average } \\
\text { Learning } \\
\text { Gains }\end{array}$ \\
\hline $\begin{array}{l}\text { LO } \\
W\end{array}$ & $\begin{array}{l}\mathrm{M}=20 \% \\
\mathrm{SD}=1.22 \\
n=5\end{array}$ & $\begin{array}{l}\mathrm{M}=62 \% \\
\mathrm{SD}=3.42 \\
n=5\end{array}$ & $42 \%$ & $\begin{array}{l}\mathrm{M}=27 \% \\
\mathrm{SD}=0.65 \\
n=11\end{array}$ & $\begin{array}{l}\mathrm{M}=62 \% \\
\mathrm{SD}=1.99 \\
n=11\end{array}$ & $34 \%$ \\
\hline $\begin{array}{l}\mathrm{ME} \\
\mathrm{D}\end{array}$ & $\begin{array}{l}\mathrm{M}=40 \% \\
\mathrm{SD}=0 \\
n=3\end{array}$ & $\begin{array}{l}\mathrm{M}=67 \% \\
\mathrm{SD}=0.58 \\
n=3\end{array}$ & $27 \%$ & $\begin{array}{l}\mathrm{M}=43 \% \\
\mathrm{SD}=0.52 \\
n=6\end{array}$ & $\begin{array}{l}\mathrm{M}=77 \% \\
\mathrm{SD}=1.54 \\
n=6\end{array}$ & $33 \%$ \\
\hline $\begin{array}{l}\mathrm{HIG} \\
\mathrm{H}\end{array}$ & $\begin{array}{l}\mathrm{M}=65 \% \\
\mathrm{SD}=0.71 \\
n=2\end{array}$ & $\begin{array}{l}\mathrm{M}=59 \% \\
\mathrm{SD}=2.47 \\
n=2\end{array}$ & $-6 \%$ & $\begin{array}{l}\mathrm{M}=64 \% \\
\mathrm{SD}=0.55 \\
n=5\end{array}$ & $\begin{array}{l}\mathrm{M}=76 \% \\
\mathrm{SD}=2.54 \\
n=5\end{array}$ & $12 \%$ \\
\hline
\end{tabular}

The data in Table 4 below represents the average learning gains for the comparison and treatment groups broken down by learning targets for the pre and post tests. Overall the comparison group scored slightly higher than the treatment group in both the "Engineering Design" and "Earthquake Content" target categories. Data for "Stress" is not available because the content was present on the pre-test, however not on the post-test. 
Table 4: Average Learning Gains Based On Learning Targets

\begin{tabular}{lcc}
\hline $\begin{array}{l}\text { Learning } \\
\text { Targets }\end{array}$ & $\begin{array}{c}\text { Comparison Group } \\
(n=10)\end{array}$ & $\begin{array}{c}\text { Treatment Group } \\
(n=22)\end{array}$ \\
\hline $\begin{array}{l}\text { Engineering } \\
\text { Design }\end{array}$ & $23 \%$ & $21 \%$ \\
$\begin{array}{l}\text { Earthquake } \\
\text { Content }\end{array}$ & $41 \%$ & $36 \%$ \\
Stress & N/A & \\
& & N/A \\
\hline
\end{tabular}

Learning gains for each individual student and the group to which that student was apart can be seen in Tables $5 \& 6$ below. This data shows each student in the context in which their cooperative learning group took place. This information will be helpful when looking at interview data later in this section. Table 5 represents data for the comparison group and Table 6 represents data for the treatment group. 
Table 5: Group Composition for Comparison Group

\begin{tabular}{|c|c|c|c|}
\hline Group & Student & Category & Learning Gain \\
\hline \multirow[t]{4}{*}{1} & $301 *$ & N/A & N/A \\
\hline & 302 & MED & $24 \%$ \\
\hline & $303 *$ & N/A & N/A \\
\hline & $304 *$ & N/A & N/A \\
\hline \multirow[t]{4}{*}{2} & 305 & MED & $24 \%$ \\
\hline & $306^{*}$ & N/A & N/A \\
\hline & $307 *$ & N/A & N/A \\
\hline & $308^{*}$ & N/A & N/A \\
\hline \multirow[t]{4}{*}{3} & 309 & LOW & $44 \%$ \\
\hline & 310 & HIGH & $-24 \%$ \\
\hline & $311 *$ & N/A & N/A \\
\hline & 312 & HIGH & $11 \%$ \\
\hline \multirow[t]{4}{*}{4} & 313 & LOW & $56 \%$ \\
\hline & $314 *$ & N/A & N/A \\
\hline & $315^{*}$ & N/A & N/A \\
\hline & $316^{*}$ & N/A & N/A \\
\hline \multirow[t]{4}{*}{5} & $317^{*}$ & N/A & N/A \\
\hline & $318 *$ & N/A & N/A \\
\hline & $319^{*}$ & N/A & N/A \\
\hline & 320 & MED & $31 \%$ \\
\hline \multirow[t]{4}{*}{6} & $321 *$ & N/A & N/A \\
\hline & 322 & LOW & $44 \%$ \\
\hline & $323 *$ & N/A & N/A \\
\hline & $324 *$ & N/A & N/A \\
\hline \multirow[t]{4}{*}{7} & $325^{*}$ & N/A & N/A \\
\hline & 326 & LOW & $45 \%$ \\
\hline & $327 *$ & N/A & N/A \\
\hline & 328 & LOW & $21 \%$ \\
\hline
\end{tabular}

* This student did not submit a permission form 
Table 6: Group Composition for Treatment Group

\begin{tabular}{|c|c|c|c|}
\hline Group & Student & Category & Learning Gain \\
\hline \multirow[t]{4}{*}{1} & $501 *$ & N/A & N/A \\
\hline & 502 & MED & $29 \%$ \\
\hline & $503 *$ & $\mathrm{~N} / \mathrm{A}$ & N/A \\
\hline & 504 & MED & $31 \%$ \\
\hline \multirow[t]{4}{*}{2} & 505 & LOW & $36 \%$ \\
\hline & 506 & $\mathrm{HIGH}$ & $43 \%$ \\
\hline & 507 & MED & $28 \%$ \\
\hline & 508 & LOW & $56 \%$ \\
\hline \multirow[t]{4}{*}{3} & 509 & LOW & $41 \%$ \\
\hline & $510^{*}$ & $\mathrm{~N} / \mathrm{A}$ & N/A \\
\hline & $511 *$ & N/A & N/A \\
\hline & $512 *$ & N/A & N/A \\
\hline \multirow[t]{3}{*}{4} & 513 & LOW & $34 \%$ \\
\hline & 514 & HIGH & $19 \%$ \\
\hline & 515 & MED & $20 \%$ \\
\hline \multirow[t]{4}{*}{5} & 516 & LOW & $49 \%$ \\
\hline & 517 & HIGH & $1 \%$ \\
\hline & $518^{*}$ & N/A & N/A \\
\hline & 519 & LOW & $27 \%$ \\
\hline \multirow[t]{4}{*}{6} & $520 *$ & N/A & N/A \\
\hline & 521 & HIGH & $-20 \%$ \\
\hline & 522 & MED & $24 \%$ \\
\hline & 523 & LOW & $41 \%$ \\
\hline \multirow[t]{4}{*}{7} & 524 & LOW & $9 \%$ \\
\hline & 525 & HIGH & $22 \%$ \\
\hline & 526 & MED & $41 \%$ \\
\hline & $527^{*}$ & N/A & N/A \\
\hline \multirow[t]{3}{*}{8} & 528 & LOW & $24 \%$ \\
\hline & 529 & HIGH & $40 \%$ \\
\hline & 530 & MED & $46 \%$ \\
\hline
\end{tabular}

*This student did not submit a permission form 


\section{Student Perception of Cooperative Learning Groups}

The first two questions on the group interaction form were used to compile the data for this section. The questions were in the form of statements with four options for students to choose from. The first statement was: Group stays on task and manages time efficiently. The second statement was: Group shares opportunities to contribute. The options to choose from can be seen in Appendix D. The data can be viewed in Table 7 below. A t-test was performed to see if the data for the two groups was statistically significant. When looking at the data for the first statement, the p-value was $<0.05$, and the $t=2.29$. This indicates that there was a statistically significant difference between student answers to the first question between the two contrast groups. On average, the treatment group felt that their groups stayed on task and managed their time more efficiently than the comparison group.

For the second question, the means were nearly the same between both groups. The comparison group had a mean of 3.22 and the treatment group had a mean of 3.18. Both values correlate to a "I agree with this statement" from the Group Interaction Evaluation form. Both the comparison and treatment groups agreed that their cooperative learning groups shared opportunities to contribute. There was no significant difference between the two groups on this statement. The data is visually represented in the bar graph in Figure 3. 
Table 7: Group Interaction Form Mean, SD and t-test Results

\begin{tabular}{|c|c|c|c|}
\hline & Comparison & Treatment & $\mathrm{t}$-test \\
\hline $\begin{array}{l}\text { Q1 } \\
\text { (4) }\end{array}$ & $\begin{array}{l}\mathrm{M}=2.9 \\
\mathrm{SD}=0.33\end{array}$ & $\begin{array}{l}\mathrm{M}=3.4 \\
\mathrm{SD}=0.58\end{array}$ & $\begin{array}{l}\mathrm{t}=2.29 \\
\mathrm{p}=0.0148 \\
\text { Statistically } \\
\text { Significant }\end{array}$ \\
\hline $\begin{array}{l}\text { Q2 } \\
\text { (4) }\end{array}$ & $\begin{array}{l}\mathrm{M}=3.22 \\
\mathrm{SD}=0.67\end{array}$ & $\begin{array}{l}\mathrm{M}=3.18 \\
\mathrm{SD}=0.66\end{array}$ & $\begin{array}{l}\mathrm{t}=0.15 \\
\mathrm{p}=0.4395 \\
\text { Not Statistically } \\
\text { Significant }\end{array}$ \\
\hline
\end{tabular}

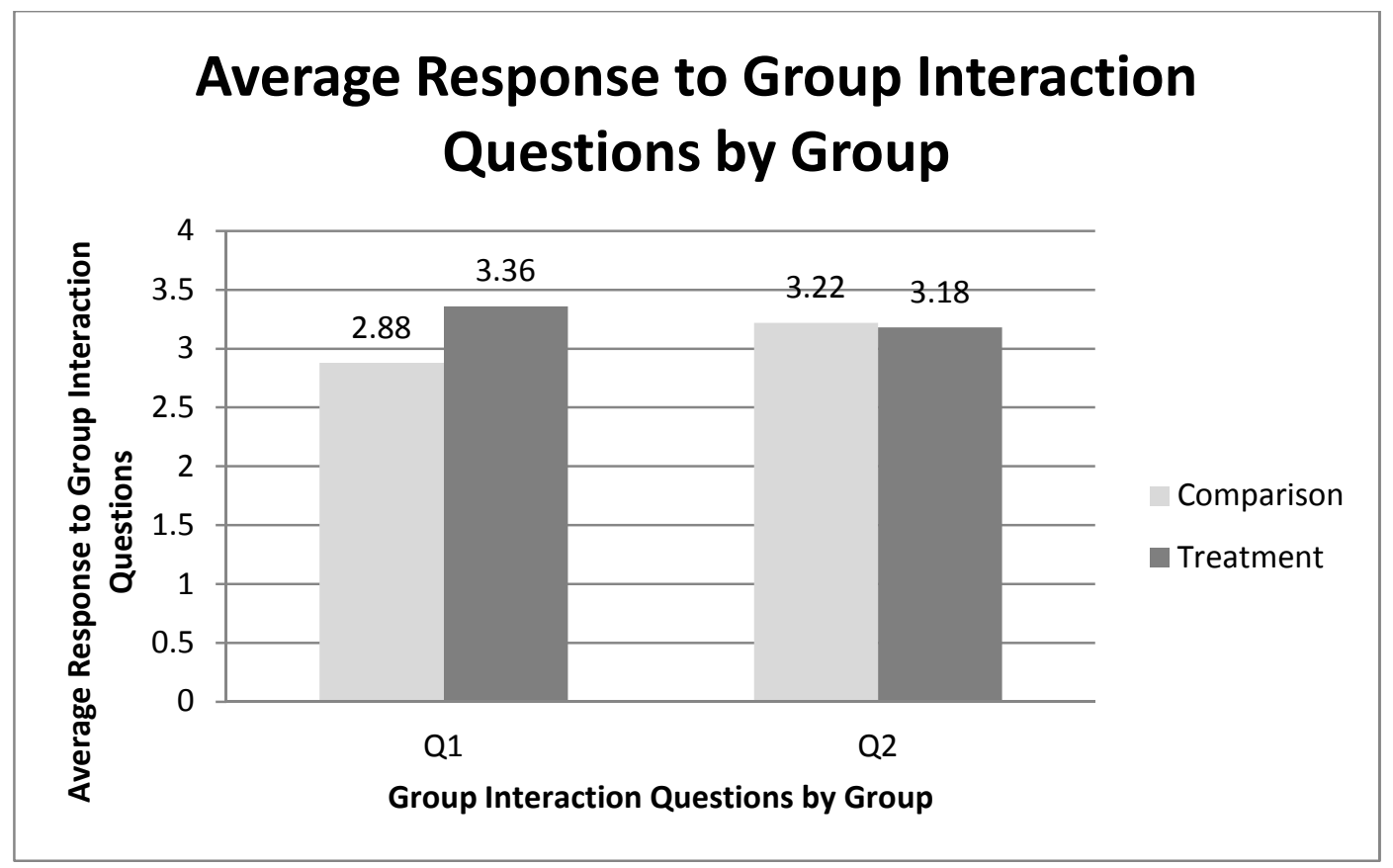

Figure 3: Graph of Average Response to Group Interaction Questions by Contrast Groups 


\section{Interview Data}

Interviews were conducted one week after both study groups had received the treatment and had completed their post-test assessments. On the day of the interview, five students had submitted their permission forms from the comparison group. The three students from the comparison group were selected due to their submission of a permission form and their availability on the day of the interview. The three interviewees that were selected from the treatment group were selected because each student was a part of the same heterogeneous cooperative learning group and present during the interview day. Interviews took place during regular school hours and lasted around 10 minutes each. The responses given to interview question number four were the only responses analyzed for this study. This question elicited responses that are best aligned with the research question posed by this study. The following quotations represent the responses from three students who were all in different groups within the comparison group. Refer back to Table 5 to see the context of each students cooperative learning group.

Question 4: Can you imagine trying to design a solution to a similar problem by yourself? What are some of the pros and cons of solving this problem as a group compared to solving it on your own?

Student 312's Response: "I could have done this on my own but I would have needed a lot more time. The pro's of working with my group were that there was less of a need to multitask and we were able to get the project done a lot quicker. The cons were that sometimes we would argue what would go where and who would be doing what. More hands could be more sloppy because people aren't paying as close of attention to what they are doing."

Student 322's Response: "I can imagine designing a solution to a similar problem by myself. Some of the pro's were that we had more design ideas 
to choose from with four people in our group. I think four people is the ideal amount for a group on a project like this, you get more help building. Some of the cons were that some of us would get off task and talk because we did not have a job to do."

Student 326's Response: "I could do it on my own but it would be a lot harder. The pros were that we were able to build a lot faster and it was easier to work and we had more ideas. The cons were that sometimes people in my group would not contribute, not everyone had a job. I think the project would have been completed better if we were working in partners."

Common themes from the three interviews in the comparison group were that working in a group was more efficient than doing it on your own and that working in a group can create some off task behavior when not everyone has a job.

The following quotations represent the responses to Question 4 from three students who were all in the same heterogeneous cooperative learning group within the treatment group. Refer back to Table 6 to see the context of each student within this cooperative learning group.

Question 4: Can you imagine trying to design a solution to a similar problem by yourself? What are some of the pros and cons of solving this problem as a group compared to solving it on your own?

Student 528's Response: "I don't think I would have been able to do it on my own, I get pretty easily distracted. I would say the pros were that we had more ideas to choose from, and we could help each other out when needed. The cons were that our group was kind of small and we only had one glue gun. I also missed a couple of days of building during the first design and we were not able to finish building our structure on time. I think having more people in the group would have helped."

Student 529's Response: "Yeah, I would have been able to do it on my own but I would have needed more time to complete it with the same criteria and constraints. The pros were that we had more ideas, faster building, I guess more efficient, and we could consult with our group members. The cons were that we did not always agree with one another 
and we would get stuck on one problem and spend too much time on that when other things could be done at the same time."

Student 530's Response: "Yes, but it would not be as efficient or well done as it would be if it were done in a group. Pros would be having group members be able to keep you on track, we had more ideas with more heads, it was faster and there was more insight. I think cons to working in a group were that there were more distractions and the size of our group was too small, when (Student 528) was sick we really fell behind only having two people to do all of the work."

The common themes represented by individuals within this one group were that working in a group presents more ideas and a way of working through problems with help from others, and building is more efficient with more than one person. The common themes within the responses to the cons of working in a group were that the size of the group may have a positive or negative effect on the groups outcomes.

\section{Summary}

There was no statistically significant difference between the class results of the comparison and treatment groups. The mean scores for the post-test of the treatment group were greater or equal to those of the comparison group in all three categories. All groups showed an increase in learning except for the disaggregated data for the "high" category of the comparison group. There was a statistically significant difference between student answers to question one on the Group Interaction Evaluation Form. Students in the treatment group felt like their cooperative learning groups stayed on task and managed their time efficiently more than the comparison group. 


\section{CHAPTER 5: DISCUSSION}

This study was designed to answer the research question: does the method of student assignment to cooperative learning groups in an inclusive middle school science classroom make a difference in students' ability to understand the engineering design process, science concepts and have an effect on student perceptions of their groups? To answer this question, the question was broken into two parts: content (engineering design process and science concepts) and group perception.

\section{Interpretation of Findings}

The data shows that there was not a statistically significant difference between the comparison and treatment group learning gains $(\mathrm{p}>0.05)$. Figure 1 graphically depicts these results and shows that there is not much difference between the comparison and treatment group pre-post scores. For both groups, the mean pre-test scores were fairly close, with a five percent difference between them. The mean post-test scores only had a six percent difference between the two groups. The pre-test and the post-test were designed to measure student understanding of the engineering design process and science concepts related to the unit. The data suggests that grouping students into heterogeneous cooperative learning groups has no significant difference than grouping students randomly.

The student who was categorized into the "high" group based on their pre-test score and who did very poorly on the post-test appeared to have not fully read the short answer questions before answering them. The answers that the student provided on the 
test were not as thoughtful as he or she has typically provided. There could have been a variety of reasons for this anomaly. This anomaly accounts for the negative learning gains that were shown in Figure 2.

On average, all students in treatment group had positive learning gains when looking at the disaggregated data based on groupings that were established by achievement on the pre-test. This shows that the treatment was not necessarily ineffective, but the method of grouping may not pose as much of a difference as using cooperative learning groups themselves.

To address the second part of the research question, dealing with student perceptions of their groups, the data suggests that the students in the treatment group had a more positive perception of how well their cooperative learning groups stayed on task and managed their time efficiently $(\mathrm{p}<0.05)$. The mean for the treatment group was 3.4 and the mean for the comparison group was 2.9. This indicates that the majority of students in the treatment group agreed with the statement or strongly agreed with the statement. The mean of 2.9 in the comparison group indicates that there was a mixture of students who agreed with the statement and who disagreed with the statement. There was no significant difference between the answers to the second statement; group shares opportunities to contribute. On average both groups had answers that either agreed with the statement or strongly agreed with the statement. Overall, it appeared that both classes had relatively positive perceptions of how their groups worked together over the course of this engineering design project. Based on student answers to these two statements, one being statistically significant and the other not, it is hard to say that there was a major 
difference between the two contrast groups perceptions of their cooperative learning groups.

\section{Limitations}

The purpose of this study was to examine two different grouping methods of students into cooperative learning groups and to see if the method of grouping had a positive effect on their learning and perceptions of their group interaction over the course of an engineering design unit. An initial assessment of this study was evaluated through the preceding data analysis section, however, several limitations are discussed to consider implications of this study on teaching in a middle school science classroom.

The small, non-randomized sample size used in this study $(n=32)$ limits the scope of the findings. The two contrast groups also had substantially different sample sizes. The comparison group had an $n$ of 10 , and the treatment group had an $n$ of 22 . The sample within the comparison group makes up about a third of all of the students that took part in the same learning experience in the class. The sample populations consisted of two intact eighth grade Earth and Space Science classes and I was not able to control how many permission slips were turned in for either class. This small sample size may not be representative of larger student populations outside of the school to which I was assigned. The implications of only having two eighth grade classes to choose from, one in which half the students were placed in a higher level math class could also have had an impact on the results of this study. 
Student absences were another possible limitation to this study. Students were working in their cooperative learning groups for the entirety of the three weeks of instruction for this unit. Some groups experienced a strain when they had members of their group that were absent and those students that were absent missed out on key instructional time that could have shown up in the data.

Finally, the pre-test and post-test instruments could pose as a limitation of this study. The tests were designed and created by myself and were only validated by my mentor teacher and one other science teacher at the school by a brief glance and read through. The questions posed on these two exams could have been structured to be more clear and straightforward. Confusion of the question could have lead to inaccurate answers. The questions were also not aligned perfectly from pre to post test. This was due to constraints with time to complete the project. I wanted to teach students about different types of stress, specifically tension and compression, however did not have enough time to teach these concepts and have students complete the engineering design experience.

\section{Conclusion}

Although the findings of this research are not consistent with the current literature studying the positive effect of heterogeneous cooperative learning groups on all student learning (Gillies, 2008), there are still many positive implications for my own practice. Through my research, I did find that cooperative learning groups were an overall positive experience for my students as suggested by Johnson and Johnson (2012). My treatment group, which was grouped heterogeneously, had average learning gains that were not 
statistically significant when compared to my comparison group which had students grouped randomly. These cooperative learning groups do provide an excellent means of differentiated instruction for a diverse classroom and there is a variety of different methods to grouping students that can be affective (Tomlinson, 2005).

This experience was a great opportunity to research teaching strategies and implement and measure their affect in my classroom. Even though I did not experience the same results as the literature suggests, I believe that heterogeneous cooperative learning has a variety of possibilities in every classroom, not just a middle school science classroom. When done correctly, this type of grouping can allow higher level learners to use their knowledge to teach lower level learners (Gillies, 2008). In turn, these lower level learners can raise questions that mid or high level learners may not have thought of but expand the discussion on a deeper level. My interview results alluded to this when Student 528 said "I don't think I would have been able to do it on my own, I get pretty easily distracted. I would say the pros were that we had more ideas to choose from, and we could help each other out when needed." This student, who was in the "low" category based on their pre-test scores, suggests that more ideas are generated within his group which can be helpful when coming up with a refined design, and discussing the designs on a deeper level.

The role of engineering design in this research project played a large part in the high engagement factor that I observed while instructing this unit. The fact that we were able to go through almost the entire engineering design process was something that not many students get to experience. In most classrooms, if you do a design project you just 
get to make one model, sometimes you don't even get to test it. My students were able to create an earthquake safe home model, test it on a shake table, see where their designs failed or needed improvement and were able to construct an entire new structure and test it. This is a long process, and presents challenges as a teacher to ensure that not only do my students get to build, but they are also receiving instruction and most of all, are learning. For the most part, my students had positive learning gains over the course of the unit, and the few students that did not, could have done so for a variety of reasons.

Based on my research, I have several more questions that have sparked my attention on cooperative learning. In the future, I could see myself conducting similar studies comparing homogeneous groups to heterogeneous groups, adding a component of structured roles within learning groups, and seeing if there are any benefits to self selected groups. I will definitely continue to incorporate engineering design as an element of my curriculum, even though it proves to be a very time consuming process.

My students were organized into cooperative learning groups for the whole year of instruction. I believe that they are an important part of a science classroom and plan on structuring my future class in the same way. Even though students are seated in groups, there is always opportunity to require individuals to do tasks on their own, but the opportunity to have students share ideas with one another is always at your fingertips.

In conclusion, my study did not produce statistically significant results based on pre-post comparison. However, this will not deter me from using this strategy as a means of differentiated instruction in my classroom. Heterogeneous cooperative learning groups 
have shown to have positive learning gains compared to individualized learning. My data did not mirror these findings but my interview results do support this. For example each student in the heterogeneous cooperative learning group had a comment about how they felt there were more ideas present when working in a group. Each student also felt like the process was more efficient than doing it on their own. From my experience with this project I could see benefits to taking the time to intentionally group my students based on their abilities. I collected data that allowed me to interpret my results and answer my question. The answer was not what I was expecting but definitely informs my practice and has made me a better educator.

\section{Recommendations}

For those that wish to conduct a similar study, I have a few recommendations. The time of year in which you conduct the study and the participants that make up your could play a significant role. My study was conducted with eighth grade students near the end of their eighth grade year. The pre-test was given in early May and the post-test was given during the first few days of June. At this point, my students only had a few days left of being in middle school and it was hard to keep them engaged with the content portion of the unit.

In addition, I would recommend constructing interview questions with more of a focus to tease out anomalies in the data. Unfortunately my interviews did not add as much insight as I had hoped. However, I still was able to acquire information that helped strengthen my study. 
Finally, I would recommend assigning roles to students within their groups and using this as an instructional technique while teaching students how to function in a cooperative learning group. Both Kagan (1989) and Johnson et al. (1980) suggest assigning roles to members of cooperative learning groups as a means of accounting for individual accountability, equal participation and simultaneous interaction. These three concepts are three of the four elements of PIES (Kagan 1998). I decided to leave this out of my study because I was curious to see how students formed their own roles within the group and who would end up taking the leadership role. However, I could see the affects of this decision early on when some students were sitting back feeling like they could not contribute and I had to spend a lot of time and energy explaining to the class that every member of their group should be doing something in order to complete the project on time. I would also recommend that you pick an engineering design project where you as an instructor or researcher can have a lot of fun observing your students working cooperatively together with peers of mixed abilities building incredible things. 


\section{References}

Bellantoni, J., Hariani, M., Seaver, D., Nagle, B., \& Wilmes, S. (2012). Issues and earth science 2 nd edition (sepup issue-oriented science). (2 ed.). New York: Lab-Aids.

Dean, C. B., Stone, B., Hubbell, E., \& Pitler, H. (2012). Classroom instruction that works: Research-based strategies for increasing student achievement (2nd ed.). Alexandria, VA: ASCD.

Gattie, D. K., \& Wicklein, R. C. (January 01, 2007). Curricular value and instructional needs for infusing engineering design into K-12 technology education. Journal of Technology Education, 19, 1, 6-18.

Gillies, R. (January 01, 2008). The effects of cooperative learning on junior high school students' behaviours, discourse and learning during a science-based learning activity. School Psychology International, 29, 3, 328-347.

Gokhale, A. A. (January 01, 1995). Collaborative learning enhances critical thinking. Journal of Technology Education, 7, 1, 22-30.

Johnson, David W., and Roger T. Johnson. "An Educational Psychology Success Story: Social interdependence theory and cooperative learning." Educational Researcher. 38.5 (2009):365-79. Web. 10 Mar. 2012. $<$ http://edr.sagepub.com/content/38/5/365.full.pdf html>.

Johnson, D. W., Skon, L., \& Johnson, R. (April 01, 1980). Effects of cooperative, competitive, and individualistic conditions on children's problem-solving performance. American Educational Research Journal, 17, 1, 83-93.

Kagan, S. (1989). The structural approach to cooperative learning. The Association for Supervision and Curriculum Development, 12-15. Retrieved from http://www.ascd.org/ASCD/pdf/journals/ed_lead/el_198912_kagan.pdf

Kagan, S., \& Kagan, M. (1998). Staff development and the structural approach to cooperative learning. In C. Brody \& N. Davidson (Eds.), Professional Development for Cooperative Learning: Issues and Approaches (pp. 103-110). New York: State University of New York.

Marzano, R. J., Pickering, D., \& Pollock, J. E. (2001).Classroom instruction that works, research-based strategies for increasing student achievement. Upper Saddle River: Prentice Hall. 
Mastropieri, M. A., Scruggs, T. E., Norland, J. J., Berkeley, S., McDuffie, K., Tornquist, E. H., \& Connors, N. (December 07, 2006). Differentiated curriculum enhancement in inclusive middle school science: Effects on classroom and highstakes tests. Journal of Special Education, 40, 3, 130-137.

Mehalik, M. M., Doppelt, Y., \& Schunn, C. D. (2008). Middle-school science through design-based learning versus scripted inquiry: Better overall science concept learning and equity gap reduction. Journal of Engineering Education, 97(1).

National Research Council (2011). A Framework for K-12 Science Education: Practices, Croscutting Concepts, Core Ideas. Washington, D.C.:National Academy Press.

Next Generation Science Standards (2013). Next generation science standards (ms-ess3 earth and human activity). Achieve, Inc. on behalf of the twenty-six states and partners that collaborated on the NGSS. Retrieved from http://www.nextgenscience.org/msess3-earth-human-activity

Next Generation Science Standards (2013). Next generation science standards (msetslengineering design). Achieve, Inc. on behalf of the twenty-six states and partners that collaborated on the NGSS. Retrieved from http://www.nextgenscience.org/msets 1-engineering-design

Oregon Department of Education (ODE). (2011) Oregon Science K-HS Content Standards. Retrieved from http://www.ode.state.or.us/wma/teachlearn/testing/scoring/guides/201112/sciscorguide_g6-8eng_1112.pdf

PPS. (2011, October 06). Roseway heights (k-8) - school enrollment facts. Retrieved from http://www.pps.k12.or.us/files/enrollmenttransfer/Roseway_Heights_data_packet.pdf

Tomlinson, C. A., \& Strickland, C. A. (2005).Differentiation in practice, a resource guide for differentiating curriculum, grades 9-12. (pp. 1-18). Alexandria, VA: Association for Supervision \& Curriculum Development. 
APPENDIX A: Pre-Test

\section{Earthquake Engineering Design Pre-Test}

Part 1: The Design Process

1) You are an engineer who was just hired as the lead engineer on a particular project. What is the correct order in which you would go about solving the problem the project was funded to address. (1 point)

a. Identify the problem, identify criteria and constraints, conduct background research, brainstorm possible solutions, select a solution that best matches the criteria, build a model or prototype, test the model, and refine the design if needed.

b. Identify the problem, build a prototype, start construction on the project.

c. Identify the problem, identify criteria and constraints, build a model, brainstorm ideas, conduct background research, select a solution that best matches the criteria, test the model, refine the design if needed.

d. Conduct background research, identify the problem, build a prototype, test the prototype, redesign if needed.

2) Read the following passage, identify the criteria needed to solve the problem: (2 Points)

You and your team have been hired to design a home that will withstand an earthquake up to a 9.0 on the Moment Magnitude Scale (MMS). The home will be built in a subdivision on the outskirts of Portland, Oregon. The base of the home must be 20ft by $20 \mathrm{ft}$ and will be at least two stories tall. The family who has hired you wants tall ceilings on the first floor, the ceiling height must be $20 \mathrm{ft}$ high. The family has bought the plot of land and is eager to see the home of their dreams in the near future. They also require that the home be constructed at a cost no more than $\$ 250,000$.

Criteria:

Criteria are things that are required for a successful solution but do not limit your design freedom.

-The home will be built in a subdivision on the outskirts of Portland, Oregon. -Must be constructed in the near future. 
Part 2: Constructing Earthquake Safe Homes

3) It is better to build a home on top of... (1 Point)
a. a thick layer of soil
b. sand
c. solid rock
d. a thin layer of soil

4) Which of the following is not a hazard that you should keep in mind when designing an earthquake safe home (1 Point)
a. soil liquefaction
b. Aftershocks
c. fire
d. price

5) Explain why using the base isolation technique between the foundation and the first floor helps buildings withstand powerful earthquakes. (2 Points)

-Increased shock absorption

-Increased flexibility, less rigid

Part 3: Design - Tension and Compression

6) View the following diagram, imagine the $300 \mathrm{lb}$ weight is placed on top of the flat board, label areas of tension and areas of compression. Draw in supports that would relieve this stress. (3 Points)

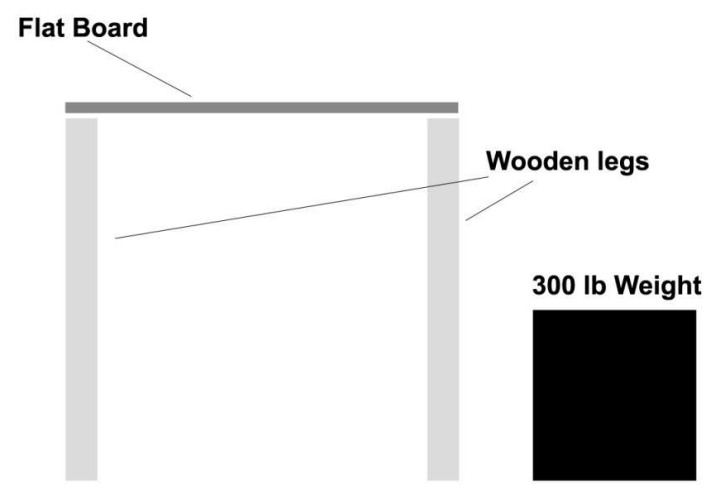


APPENDIX B: Post-Test

Earthquake Engineering Design Test

Multiple Choice: Choose the best answer

1) You are an engineer who was just hired as the lead engineer on a particular project. What is the correct order in which you would go about solving the problem the project was funded to address?

a. Identify the problem, build a prototype, start construction on a project

b. Identify the problem, identify criteria and constraints, conduct background research, brainstorm solutions, select a solution that best matches the criteria, build a model or prototype, test the model, and refine design if needed.

c. Identify the problem, identify criteria and constraints, build a model, brainstorm ideas, conduct background research, select a solution that best matches the criteria, test model

d. Conduct background research, identify the problem, build a prototype, test the prototype, redesign if needed.

2) Which of the following are ONLY criteria for a successful design

a. Durable design, practical design, base isolation, 20x20 $\mathrm{cm}$ base

b. $20 \times 20 \mathrm{~cm}$ base, first floor must be $20 \mathrm{~cm}$ high, total height at least $35 \mathrm{~cm}$ tall, must be constructed in two class periods or less

c. Durable design, practical design, base isolation, must be constructed in two class periods or less

d. $20 \times 20 \mathrm{~cm}$ base, first floor $20 \mathrm{~cm}$ high, total height at least $35 \mathrm{~cm}$ tall, 1 door and at least two windows

3) Which of the following are ONLY constraints for a successful design

a. Durable design, practical design, base isolation, 20x $20 \mathrm{~cm}$ base

b. $20 \times 20 \mathrm{~cm}$ base, first floor must be $20 \mathrm{~cm}$ high, total height at least $35 \mathrm{~cm}$ tall, must be constructed in two class periods or less

c. Durable design, practical design, base isolation, must be constructed in two class periods or less

d. $20 \times 20 \mathrm{~cm}$ base, first floor $20 \mathrm{~cm}$ high, total height at least $35 \mathrm{~cm}$ tall, 1 door and at least two windows

4) It is better to build a home on top of...

a. A thick layer of soil

b. Sand

c. Solid rock

d. A thin layer of soil 
5) Which of the following is not a hazard that you should keep in mind when designing an earthquake safe home
a. Soil liquefaction
b. Aftershocks
c. Fire
d. Price

6) What type of seismic waves were we simulating in our model
a. P-waves
b. Tidal Waves
c. Surface Waves
d. S-waves

7) What is the difference between a $P$ and $S$ wave

a. $\mathrm{S}$ waves arrive first and travel at faster speeds than $\mathrm{P}$ waves

b. P waves arrive first and do not cause as much up and down or side to side movement as $S$ waves

c. There are no such things as seismic waves

d. None of the above

8) What type of earthquake were we trying to simulate and how long were the intervals of shaking? (2 Points)

A mega-thrust earthquake. The intervals of shaking were a 90 second main earthquake with two 15 second aftershocks.

9) Explain why using the base isolation technique between the foundation and the first floor helps buildings withstand powerful earthquakes. (2 Points)

Base isolation allows the building to be more flexible, and less rigid. The rubber pads or springs help the building absorb some of the shock from the intense ground shaking.

10) Describe how your group used teamwork and cooperation to complete the project, how successfully did you cooperate, and would you have been able to complete the project with the same criteria and constraints by yourself? (3 Points)

1. Describes how their group used teamwork and cooperation to complete the project.

2. Describes how successfully they cooperated with their group

3. Describes how they would have not been able to complete the project with the same criteria and constraints on their own because there would not be enough time among other things. 


\section{APPENDIX C: Student Interview Questions}

The following questions will be asked of each participant:

1. Do you remember the question your group was trying to address in our design activity?

If so, can you explain to me? (Follow up with a reminder if student can't answer)

a. Student can restate the problem accurately

Comments:

b. Student can somewhat restate the problem

Comments:

c. Student does not remember the problem presented

Comments:

2. How did your group go about trying to answer the problem?

3. What did each of the members of your group contribute while trying to answer the problem?

What did you contribute?

\begin{tabular}{|l|c|}
\hline \multicolumn{1}{|c|}{ Group Members } & Interviewee \\
\hline Student A: & \\
Student B: & \\
Student C: & \\
& \\
\hline
\end{tabular}

4. Can you imagine trying to design a solution to similar problem by yourself? What are some of the pros and cons of solving this problem as a group compared to solving it on your own?

5. Is there something that you learned from a group member that you did not know before you started this project? 


\section{APPENDIX D: Evaluating Group Interaction Form}

This form was adapted from Group Interaction Student Sheet 1, from the SEPUP Curriculum. All students in both groups with be asked to evaluate their groups at the end of the unit.

NAME

DATE

\section{Procedure:}

Use the table below to rate your group's performance. The score is based on a 4 point scale. Read the statement in bold and then circle the answer that you feel answers the statement. Give evidence for your scores by answering Questions 1 and 2 below.

\begin{tabular}{|c|l|}
\hline \multicolumn{2}{|l|}{ Statement: Group stays on task and manages time efficiently } \\
\hline Score & Meaning \\
\hline 1 & I strongly disagree with the statement \\
\hline 2 & I disagree with the statement \\
\hline 3 & I agree with the statement \\
\hline 4 & I strongly agree with the statement \\
\hline
\end{tabular}

\begin{tabular}{|c|l|}
\hline \multicolumn{2}{|l|}{ Statement: Group shares opportunities to contribute } \\
\hline Score & Meaning \\
\hline 1 & I strongly disagree with the statement \\
\hline 2 & I disagree with the statement \\
\hline 3 & I agree with the statement \\
\hline 4 & I strongly agree with the statement \\
\hline
\end{tabular}


1. Give some examples of how you managed the task and time efficiently.

2. Give some examples of how your group shared opportunities to contribute to the activity. Your examples might include times when you or your group members: respected and treated others with courtesy; helped each other do the work; shared the work (not having one person do all of the work alone); or stayed open-minded and willing to compromise. 
APPENDIX E: IRB Application and Approval for Human Subjects

\section{Human Subjects Research Review Committee}

Proposal Application for Arman Werth

\section{Project Title and Prospectus}

Grouped to Achieve: Are there benefits to assigning students to heterogeneous cooperative learning groups based on pre-test scores?

Small learning groups have been in existence since the beginning of the human race. These groups have grown in their variance and complexity overtime. Cooperative learning has been one of the most widely used instructional practices around the world since the early 1980's. Classrooms are getting more diverse every year and instructors need a way to take advantage of this diversity to improve learning. The purpose of this study is to see if heterogeneous cooperative learning groups based on student achievement can be used as a differentiated instruction strategy to increase students' ability to demonstrate knowledge of science concepts and ability to take part in the engineering design process. This study will include two different groups made up of two different middle school science classrooms of 25-30 students. These students will be given a problem that they will need to design a solution for in cooperative learning groups. One class will be put into heterogeneous cooperative learning groups based on student's pre-test scores. The other class will be grouped based on random assignment. The study will measure the difference between each class's pre-post gains and student's responses to interview questions addressing the design process and the interaction between group members while participating in the design process. Every student will evaluate their group interaction and these results will also be examined in the study. Findings from this study can contribute to the current body of literature on best practices for instruction of diverse learners in cooperative learning groups.

\section{Type of Review}

This research qualifies for an exemption of review, as it only involves research on the effectiveness of instructional techniques in an established educational environment. Student confidentiality and anonymity will be prioritized and managed through password protected computer files and locked cabinet storage throughout the collection and analysis of all participation data, interviews, and surveys. 


\section{Subject Recruitment}

This research will take place in two to four middle school classes at Roseway Heights

School in the Portland Public School District. Student participants will be in the $6^{\text {th }}$ or $8^{\text {th }}$ grade with demographics representative of the greater Portland metro area. Intact classes with pre-assigned students will make up the study groups as opposed to a random assignment. These classes typically have a student population of approximately 30 students, giving a total sample size of approximately 60 to 120 students. All students in each 6th grade Life Science class period and $8^{\text {th }}$ grade Earth and Space Science class period will be invited to participate in the research via personal correspondence (in-class) and letters to take home in late April, 2013. All students who return a signed Informed Parental Consent Form will be included in the study.

\section{First-Person Scenario}

Student X (male, 12yrs old): "Right after spring break I took home a letter about a new research study about science education and my mom said I could participate. I didn't know what the study was about and we didn't do anything different in class except we switched seats into new table groups at a different time of the month than we normally $d o$. We took a pre-test before we started our new unit, and then a test after we were done with the unit. My score on the pre-test was not that great since I am not really into nature and stuff. We took a similar test at the end of the unit and I did a lot better. Then, Mr. Werth, the Life Science student teacher, asked if he could interview me about the engineering design project we had done. I said yes and later in the week he pulled me out of core for 15 minutes and we went to Mr. Lindenmeyer's classroom. There were 5 other students in Mr. Lindenmeyer's class who said they did interviews with Mr. Werth too, but we didn't do them at the same time. We sat down across from each other at my usual table group so I could sit in my usual seat. This was during Mr. Lindenmeyer's free period and he was sitting at his desk and the classroom door was propped open. Mr. Werth asked me a few questions about how my day and week were going and then asked me 5 questions about my group and what we learned from each other and about the design process. I talked for a while about how my group interacted and how I learned a lot from my classmates while they also listened to my ideas. At the end of the interview I thought it was really cool that Mr. Werth took the time to ask me questions about how I felt about my group and I was really glad I had the chance to participate."

\section{Potential Risks and Safeguards}

There are no potential risks anticipated for subjects in this study. Students will not be academically or socially penalized if they opt to not participate in this study and those students will still be a part of the treatment. However, their data will not be included in 
the study. Safeguards for risk prevention include anonymity and privacy of all student personal information in data collected regarding student participation and interview/survey responses.

\section{Potential Benefits}

All students will benefit from increases in science classroom learning, regardless of their participation in this study. Those students participating in interviews will benefit from the opportunity to share their personal thoughts and opinions of the learning environment and teaching methods. No academic or material rewards or compensation will be available to participants, including but not limited to grade increases or extra credit. The benefit of the study to the professional community of science educators includes an increase in

knowledge about the role of cooperative learning groups as a means of differentiation in a science classroom.

\section{Confidentiality, Records \& Distribution}

Any information that is obtained in connection with this study and that can be linked to, or identify student participants will be kept confidential. This information will be kept confidential by replacing students' names with unique identification numbers in all reported data and results. All information will be stored in a locked cabinet or passwordprotected electronic format during and after data collection. Interview recordings and transcripts, using voice-to-text software will also be maintained in a password-protected electronic format. Secure transportation of records from the classroom to the researcher's home or campus will occur by using a locked briefcase holding all paper and computerbased information. Data and records shall be kept on file at the Portland State University Center for Science Education in a locked cabinet for a minimum of three years after the completion of research and will be destroyed through shredding of paper documents and permanent deletion of electronic files.

\section{Training and Experience}

This researcher is being trained through the PSU Graduate School of Education and Center for Science Education to work with secondary school students, assess them properly and employ the most current teaching strategies found in professional literature. I will be working with a veteran, cooperating teacher in the classroom in addition to being observed by a University Supervisor and advised by the PSU faculty on my advisory committee. 


\section{Educational Research on Science Learning}

Your child is invited to participate in an educational research study conducted by Arman Werth from Portland State University. The Portland Public School District has welcomed this research to gain a better understanding of science teaching and learning. In partnership with Portland State University, the Portland Public School District, and Roseway Heights K-8, the purpose of this study is to improve science instruction and provide an opportunity for an enriching experience for your child.

The researcher hopes to learn how a specific teaching method might influence students' understanding of science. This study is being conducted in partial fulfillment of the requirements for a Master's degree under the supervision of William Becker, Ph.D. Your child was selected as a possible participant in this study because of his/her enrollment in Mr. Lindenmeyer's Life Science or Earth and Space Science course at Roseway Heights School.

All students enrolled in the class will participate in the same learning activities. This study will analyze student work collected during three weeks of instruction. By signing this consent form, you give permission for your child's work to be analyzed. Your child may also be asked to be interviewed by the researcher for about 15 minutes during school hours. Any information that is obtained in connection with this study and that can be linked to your child or identify your child will be kept confidential. This information will be kept confidential by replacing students' names with unique identification numbers. All information will be stored in a locked cabinet, or password-protected electronic format. After the completion of this research project, the data will be kept on file for a maximum of three years at Portland State University.

Your child's participation is voluntary. He/she does not have to take part in this study, and it will not affect his/her final grade, relationship with the teacher, school or with PPS. Also, you may withdraw your permission for your child to participate from this study at any time. Likewise, your child may withdraw his/her consent at any time.

If you have questions or concerns about your child's participation in this study, please contact Patrick Lindenmeyer at Roseway Heights School, 7334 NE Siskiyou St., Portland, OR 97213, phone \#503.916.5600. If you have concerns about your child's rights as a research subject, please contact Research and Strategic Partnerships, Market Center Building $6^{\text {th }}$ floor, Portland State University, (503) 725-4288.

Thank you for considering this request.

Sincerely yours,

Arman Werth

Please keep this page for your records. 


\section{Consent Form}

Please sign this page and return it to Mr. Lindenmeyer.

Your signature indicates that you have read and understand the above information and agree to let your child's work be analyzed as part of this study. Your child will participate in classroom activities regardless of the inclusion of their work in the study. The researcher will provide you with a copy of this form for your own records.

Child's Name

(circle one)

(circle one)
Life Science Period: AM or PM

Earth \& Space Period : AM or PM

Signature of Parent/Guardian

Date

Print name of Parent/Guardian 


\section{Informed Student Consent Form}

You are invited to participate in an educational research study conducted by Mr. Werth from Portland State University. The purpose of this study is to improve science teaching and provide an opportunity for an engaging experience for you.

My goal is to learn how a specific teaching method might influence your understanding of a scientific concept. This study is part of my educational experience at Portland State and will help me earn my Master's degree in Science Education.

You will still be participating in all of the same learning activities as other students even if you decide to not sign this form. However, if you do sign the form, you are giving me permission to use data that I collect in my research project while keeping your identities private. You may also be asked to be interviewed by me for about 15 minutes during school hours to ask you some questions about your learning experience.

Your participation is completely voluntary. If you do not take part in this study, it will not affect your relationship with me, or your grade in anyway. If at any point you decide to not to allow me to use your data after signing this form, I will not use that data.

Thank you for considering this request.

Sincerely yours,

Mr. Werth

Your signature indicates that you have read and understand the above information and agree to participate in this study. You will participate in classroom activities regardless of your participation in the study. I will provide you with a copy of this form for your own records.

Name:

Life Science Period: AM or PM (circle one)

Earth \& Space Period : AM or PM (circle one)

Signature:

Date: 
These interview questions are designed to evaluate student's perceived effectiveness of the strategies used in the treatment. The validity of these questions will be evaluated by two science education research professionals. The following questions will be asked of each participant:

1. Do you remember the question your group was trying to address in our design activity? If so, can you explain to me? (Follow up with a reminder if student can't answer)

a. Student can restate the problem accurately

Comments:

b. Student can somewhat restate the problem

Comments:

c. Student does not remember the problem presented

Comments:

2. How did your group go about trying to answer the problem?

3. What did each of the members of your group contribute while trying to answer the problem?

What did you contribute?

\begin{tabular}{|l|c|}
\hline \multicolumn{1}{|c|}{ Group Members } & Interviewee \\
\hline Student A: & \\
Student B: & \\
Student C: & \\
& \\
\hline
\end{tabular}

4. Can you imagine trying to design a solution to similar problem by yourself? What are some of the pros and cons of solving this problem as a group compared to solving it on your own?

5. Is there something that you learned from a group member that you did not know before you started this project? 
This form was adapted from Group Interaction Student Sheet 1, from the SEPUP Curriculum. All students in both groups with be asked to evaluate their groups at the end of the unit.

NAME

DATE

\section{Procedure:}

Use the table below to rate your group's performance. The score is based on a 4 point scale. Read the statement in bold and then circle the answer that you feel answers the statement. Give evidence for your scores by answering Questions 1 and 2 below.

\begin{tabular}{|c|l|}
\hline \multicolumn{2}{|l|}{ Statement: Group stays on task and manages time efficiently } \\
\hline Score & Meaning \\
\hline 1 & I strongly disagree with the statement \\
\hline 2 & I disagree with the statement \\
\hline 3 & I agree with the statement \\
\hline 4 & I strongly agree with the statement \\
\hline
\end{tabular}

\begin{tabular}{|c|l|}
\hline \multicolumn{2}{|l|}{ Statement: Group shares opportunities to contribute } \\
\hline Score & Meaning \\
\hline 1 & I strongly disagree with the statement \\
\hline 2 & I disagree with the statement \\
\hline 3 & I agree with the statement \\
\hline 4 & I strongly agree with the statement \\
\hline
\end{tabular}


1. Give some examples of how you managed the task and time efficiently.

2. Give some examples of how your group shared opportunities to contribute to the activity. Your examples might include times when you or your group members: respected and treated others with courtesy; helped each other do the work; shared the work (not having one person do all of the work alone); or stayed open-minded and willing to compromise. 


\section{Portland State University HSRRC Memorandum}

\section{Portland State

To: Melissa Potter/Arman Werth

From: Todd Bodner, Chair, HSRRC 2013

Date: February 20, 2013

Re: $\quad$ Your HSRRC application titled, "Grouped to Achieve: Are there benefits to assigning students to heterogeneous cooperative learning groups based on pre-test scores" (HSRRC Proposal \#132488)

In accordance with your request, the Human Subjects Research Review Committee has reviewed your proposal for compliance with DHHS policies and regulations covering the protection of human subjects. The committee is satisfied that your provisions for protecting the rights and welfare of all subjects participating in the research are adequate, and your project is approved.

Please note the following requirements:

Changes to Protocol: Any changes in the proposed study, whether to procedures, survey instruments, consent forms or cover letters, must be outlined and submitted to the Chair of the HSRRC immediately. The proposed changes cannot be implemented before they have been reviewed and approved by the Committee.

Continuing Review: This approval will expire February 20, 2014, one year from the approval date. It is the investigator's responsibility to ensure that a Continuing Review Report (available in RSP) of the status of the project is submitted to the HSRRC approximately two months before the expiration date, and that approval of the study is kept current. 
Adverse Reactions: If any adverse reactions occur as a result of this study, you are required to notify the Chair of the HSRRC immediately. If the problem is serious, approval may be withdrawn pending an investigation by the Committee.

Completion of Study: Please notify the Chair of the Human Subjects Research Review Committee (campus mail code RSP) as soon as your research has been completed. Study records, including protocols and signed consent forms for each participant, must be kept by the investigator in a secure location for three years following completion of the study.

If you have questions or concerns, please contact the HSRRC at hsrrc@pdx.edu or (503) $725-2243$.

cc: graduate studies 